\title{
Secular Trends of Global Burden of Violence, 1990-2015: In Spite of Successes, Women and Children Are Highly Affected in Low- and the Middle-Income Countries
}

\author{
Alireza Salehi, MD, MPH, $\mathrm{PhD}^{1}$; Hossein Molavi Vardanjani, $\mathrm{PhD}^{2^{*}}$ \\ ${ }^{1}$ Research Center for Traditional Medicine and History of Medicine, Shiraz University of Medical Sciences, Shiraz, Iran \\ ${ }^{2} \mathrm{MD} / \mathrm{MPH}$ Program, Shiraz Medical School, Shiraz University of Medical Sciences, Shiraz, Iran
}

\begin{abstract}
Background: Violence is a challenging modern epidemic worldwide. Less evidence is available on the populations most affected by violence in recent decades. The aim of the study was to ecologically investigate temporal trends of the global burden of violence according to gender, age group, and socio-demographic development.

Methods: Data on the age- and gender-specific rates of country-level disability adjusted life years (DALYs) attributable to different types of violence i.e. interpersonal violence (IV), and collective violence (CV) and legal interventions were retrieved from online database provided by the global burden of diseases project. Countries were categorized according to their socio-demographic index (SDI). Incidence rate ratio (IRR) per one year was estimated according to age groups, genders and SDI categories applying Poisson regression modeling.

Results: The highest decrease of the DALYs attributable to IV was observed for the under-five-years age group and then for 5-14-years in both genders, globally. Considering the $\mathrm{CV}$, estimated IRRs were significant only for the under-five-years age group, which was at 1.30 (95\% Cl: 1.20, 1.40, per 10 years) for girls and 1.29 (95\% Cl: $1.21,1.39$, per 10 years) for boys.

Conclusion: The rate of DALYs due to IV has been more decreasing among women and children during the recent decades. By the next 10 years, the attributed DALYs to CV would increase up to $120 \%$. Children, adolescents and women are highly affected by CV in countries with middle-low and middle social development in the recent decades.

Keywords: Child, Interrupted time series analysis, Violence, Women

Cite this article as: Salehi A, Molavi Vardanjani H. Secular trends of global burden of violence, 1990-2015: in spite of successes, women and children are highly affected in low- and the middle-income countries. Arch Iran Med. 2020;23(4 suppl 1):S1-S5. doi: 10.34172/aim.2020.s1.
\end{abstract}

Received: February 25, 2019, Accepted: October 12, 2019, ePublished: April 1, 2020

\section{Introduction}

Violence is a challenging modern epidemic and one of the most important causes of disability adjusted life years (DALYs). ${ }^{1,2}$ The relative burden of violence would be expected to significantly increase in the future years. ${ }^{3}$

Various preventive programs have been introduced during recent decades to address various types of violence. ${ }^{3-6}$ In addition to national prevention and control programs, several global collaborations and programs have been designed and implemented to prevent and control violence. $^{3}$

Despite the national and international efforts, the burden of some types of violence have been increasing during recent decades. ${ }^{1,2,7}$ Consequently, promotion of current violence preventive and interventional public health programs is highly appreciated. ${ }^{3}$ However, effective promotion of any public health program has to be founded on a robust knowledge of the current situation. ${ }^{8}$

The most recent situation analysis of the epidemic of violence is "the global status report on violence prevention 2014", which mainly focuses on the availability of data, preventive services and programs. ${ }^{3}$ However, evidence on the most affected or high risk groups is scarce, mainly due to lack of qualified primary data. $2,9,10$

The global burden of diseases (GBD) project provides the best of available data on the burden of some major types of violence for almost all countries for recent decades. ${ }^{1}$ Therefore, there is now a possibility to ecologically investigate the temporal trends of the burden of violence in terms of DALYs attributed to the major types of violence in different subpopulations. It would provide evidence on the most affected subpopulations and high risk groups, to be considered as target populations of the future violence preventive programs.

This study aims to investigate the temporal trends of the global burden of violence in different subpopulations according to gender, age group, and socio-demographic development. We reanalyzed the data provided by the GBD project.

\section{Materials and Methods}

This study was a secondary data analysis of available data from the official online database of the GBD project (Supplementary file 1). ${ }^{11}$ Temporal trends of burden of 
violence were analyzed.

Age- and gender-specific rates of DALYs (per 100000 populations) attributed to each type of violence, including interpersonal violence (IV including dating, domestic, and sexual violence and stalking), and violence due to collective and legal interventions (CV) were retrieved by country. The definition of IV was based according to the $\mathrm{WHO}$ as violence between individuals but not large groups. ${ }^{12}$ Collective and legal interventions, hereafter collective violence $(\mathrm{CV})$, was also defined according to the $\mathrm{WHO}$ as violence committed by large groups or violence due to armed war. ${ }^{12,13}$

As social development of countries is a major determinant of violence, stratified analyses were done according to different levels of social development. In this study, sociodemographic index (SDI) was considered as a measure of social development. Data on SDI were also retrieved from the GBD project database. SDI is a combination measure of the per capita income, the highest degree of education which has been completed by the population and the total fertility rate in a region. It is a measure of sociodemographic development of a geographic region which varies from zero to one, representing the lowest and highest socio-demographic development, respectively. ${ }^{14}$ SDI values were categorized according to the recommended categorization by the GBD collaboration.

Retrieved data were reorganized in a long shape dataset which consisted of six variables including "type of violence" (i.e. interpersonal violence, and CV), "age group" (under 5 years, 5-14 years, 15-19, 20-24, 25-29, 30-34, 35-39, 40-44, 45-49, 50-69, and older than 70 years), gender, "calendar year" (1990, 1995, 2000, 2005, 2010, and 2015), "socio-demographic category" (categorized as high, high-middle, middle, middle-low, and low), "crude rate of DALYs per 100000 population" and "age-standardized rate of DALYs per 100000 population".

Considering two different types of violence, two Poisson regressions were fitted, as violence type-specific cured rate was considered as dependent variable, and calendar year, SDI, gender, age group and their interaction terms were entered into the model as independent variables. Considering the significance of interaction term in the abovementioned models, stratified analysis was applied. Stratification was done according to the age groups, gender and SDI categories. Consequently, stratumspecific Poisson regressions were fitted considering types of violence. To estimate the overall slope of each of the stratum-specific trend lines, "calendar year" was defined as the only predictor variable in each model. Estimated incidence rate ratios (IRRs) and 95\% confidence intervals (CIs) were estimated. Annual percent change (APC) was calculated using APC $=(1-I R R) * 100$. Statistically significant APCs and their 95\% CI were reported. Data analysis was done using Stata software (StataCorp LP. USA, version 11.2).

\section{Results}

Interpersonal Violence

The overall estimated IRR for calendar year was at 0.989 (95\% CI: $0.988,0.991)$. The IRR was estimated at 0.968 (95\% CI: 0.946, 0.991) for SDI (High SDI was defined as reference category) and at 3.21 (95\% CI: 2.99, 3.46) for gender (Female was defined as reference gender). Effect of the SDI was different between males and females $(P=$ 0.001). As a result of the effect of SDI on the burden of IV, the rate of DALYs was decreasing across different levels of socio-demographic development.

Almost all estimated IRRs for age groups to predict the rate of DALYs were statistically significant and ranged from 0.4 (95\% CI: $0.39,0.42)$ for $5-14$ years to 3.22 (95\% CI: $3.15,3.28)$ for $20-24$ years compared to under 5 years. Estimated IRR were increasing up to 25 years and then started to decline with increasing age. It was estimated at 0.46 (95\% CI: $0.45,0.48)$ for the $70+$ year population. Considering these results, the trends of age- and genderspecific DALYs rates were separately analyzed according to the level of socio-demographic development (Table 1).

According to the trend analyses, the crude rate of DALYs rate was decreasing across different SDI categories as well as most of age groups. From a global perspective, the highest decrease was observed for the under-five-years age group and then for 5-14-years in both genders. Considering socio-demographic development, the highest decreases were estimated for countries with middle and high-middle socio-demographic development for the under-five-years age group. The lowest decrease was estimated for countries with low SDI.

\section{Collective Violence and Legal Interventions}

The overall estimated IRR for calendar year was at 1.02 (95\% CI: 1.01, 1.03). The IRR was estimated at 3.20 (95\% CI: 3.18, 3.22) for SDI (High SDI was defined as reference category) and at 3.53 (95\% CI: 3.49, 3.58) for gender (Female was defined as reference gender). The effect of the SDI was different between males and females $(P=0.019)$. As a result of the effect of SDI on the burden of this type of violence, rate of DALYs was rising across different levels of socio-demographic development except for high and high-middle SDI categories.

Almost all estimated IRRs for age groups to predict rate of DALYs were statistically significant and ranged from 0.53 (95\% CI: $0.51,0.55)$ for both $70+$ and 5-14 years, to 2.68 (95\% CI: $2.63,2.73)$ for 20-24 years compared to the under 5 -years group. Estimated IRR were increasing up to 25 years and then started to decline with increasing age. It was estimated at 0.91 (95\% CI: $0.88,0.93)$ for the 45-49 year population. Again, considering the significant interactions of age, gender and SDI, the trends of ageand gender-specific DALYs rates were separately analyzed according to socio-demographic development (Table 2).

The only significant percent changes at the global level 
Table 1. Percent Change (Per 10 Years)* of DALYs Rate Attributed to Interpersonal Violence, 1990-2015, According to the SDI and Gender

\begin{tabular}{|c|c|c|c|c|c|c|c|}
\hline Age (y) & Gender & L-SDI & LM-SDI & M-SDI & HM-SDI & H-SDI & Global \\
\hline \multirow{2}{*}{$<5$} & M & $-0.15(0.21,0.09)$ & $-0.32(0.39,0.26)$ & $-0.47(0.53,0.4)$ & $-0.43(0.49,0.38)$ & $-0.15(0.22,0.08)$ & $-0.34(0.41,0.38)$ \\
\hline & $\mathrm{F}$ & $-0.15(0.21,0.09)$ & $-0.26(0.34,0.21)$ & $-0.50(0.60,0.47)$ & $-0.48(0.54,0.42)$ & $-0.19(0.25,0.11)$ & $-0.38(0.44,0.31)$ \\
\hline \multirow{2}{*}{$5-14$} & M & NS & NS & $-0.20(0.28,0.12)$ & $-0.30(0.37,0.22)$ & $-0.23(0.34,0.12)$ & $-0.20(0.29,0.18)$ \\
\hline & $\mathrm{F}$ & NS & $-0.15(0.28,0.02)$ & $-0.24(0.34,0.14)$ & $-0.30(0.40,0.20)$ & $-0.24(0.36,0.11)$ & $-0.24(0.34,0.13)$ \\
\hline \multirow{2}{*}{ 15-19 } & M & NS & NS & $0.08(0.04,0.1)^{\$}$ & $-0.10(0.13,0.08)$ & $-0.27(0.31,0.23)$ & $-0.06(0.09,0.02)$ \\
\hline & $\mathrm{F}$ & $-0.09(0.18,0.02)$ & $-0.09(0.17,0.02)$ & NS & $-0.15(0.22,0.09)$ & $-0.26(0.34,0.20)$ & $-0.13(0.20,0.06)$ \\
\hline \multirow{2}{*}{$20-24$} & M & NS & $0.05(0.01,0.08)$ & $0.05(0.01,0.08)$ & $-0.13(0.15,0.11)$ & $-0.21(0.24,0.18)$ & $-0.07(0.09,0.03)$ \\
\hline & $\mathrm{F}$ & $-0.12(0.19,0.06)$ & $-0.08(0.14,0.01)$ & $-0.13(0.20,0.05)$ & $-0.20(0.25,0.14)$ & $-0.21(0.26,0.15)$ & $-0.14(0.20,0.08)$ \\
\hline \multirow{2}{*}{$25-29$} & M & NS & NS & NS & $-0.14(0.16,0.12)$ & $-0.19(0.22,0.16)$ & $-0.07(0.09,0.05)$ \\
\hline & $\mathrm{F}$ & $-0.11(0.18,0.05)$ & $-0.08(0.15,0.02)$ & $-0.09(0.16,0.02)$ & $-0.20(0.25,0.13)$ & $-0.20(0.25,0.13)$ & $-0.14(0.20,0.08)$ \\
\hline \multirow{2}{*}{$30-34$} & M & NS & NS & NS & $-0.15(0.17,0.12)$ & $-0.21(0.23,0.17)$ & $-0.08(0.11,0.05)$ \\
\hline & $\mathrm{F}$ & $-0.11(0.17,0.03)$ & $-0.09(0.17,0.02)$ & $-0.13(0.21,0.05)$ & $-0.23(0.30,0.17)$ & $-0.20(0.26,0.14)$ & $-0.18(0.24,0.11)$ \\
\hline \multirow{2}{*}{$35-39$} & M & NS & NS & NS & $-0.17(0.20,0.14)$ & $-0.23(0.27,0.20)$ & $-0.10(0.14,0.07)$ \\
\hline & $\mathrm{F}$ & NS & $-0.09(0.17,0.03)$ & $-0.12(0.20,0.05)$ & $-0.24(0.31,0.18)$ & $-0.22(0.28,0.16)$ & $-0.18(0.25,0.11)$ \\
\hline \multirow{2}{*}{$40-44$} & M & NS & NS & NS & $-0.20(0.23,0.17)$ & $-0.22(0.26,0.19)$ & $-0.13(0.17,0.10)$ \\
\hline & $\mathrm{F}$ & NS & $-0.11(0.18,0.03)$ & $-0.13(0.22,0.05)$ & $-0.24(0.31,0.16)$ & $-0.22(0.28,0.16)$ & $-0.20(0.27,0.12)$ \\
\hline \multirow{2}{*}{$45-49$} & M & NS & $-0.07(0.11,0.02)$ & $-0.08(0.12,0.04)$ & $-0.22(0.26,0.18)$ & $-0.16(0.20,0.12)$ & $-0.13(0.17,0.09)$ \\
\hline & $\mathrm{F}$ & NS & $-0.12(0.19,0.04)$ & $-0.12(0.21,0.02)$ & $-0.23(0.31,0.15)$ & $-0.16(0.22,0.09)$ & $-0.17(0.24,0.08)$ \\
\hline \multirow{2}{*}{$50-69$} & M & $0.07(0.02,0.12)$ & NS & NS & $-0.15(0.22,0.08)$ & $-0.13(0.18,0.07)$ & $-0.10(0.15,0.05)$ \\
\hline & $\mathrm{F}$ & NS & NS & NS & $-0.17(0.21,0.12)$ & $-0.17(0.25,0.08)$ & NS \\
\hline \multirow{2}{*}{+70} & M & $0.15(0.04,0.22)$ & NS & NS & $-0.24(0.34,0.14)$ & NS & NS \\
\hline & $\mathrm{F}$ & NS & NS & NS & $-0.47(0.52,0.41)$ & NS & NS \\
\hline
\end{tabular}

M, Male; F, Female; NS, Not significant at 0.05 alpha level; SDI, socio-demographic index; L, low; LM, middle-low; $M$, middle; $M H$, middle-high; $H$, high.

"Percent change per 10 years was reported. In cases of decreasing trends, percent change was reported as a negative number (i.e., -percent change).

$\$$ Bolded fonts depict an increasing trend.

(per 10 years) were estimated for the under-five-years age group which was at 0.3 (95\% CI: $0.2,0.4)$ for girls and 0.29 (95\% CI: $0.21,0.39$ ) for boys. This increasing trend was observed in spite of the decreasing trend in high, high-middle and low SDI countries. It was mainly due to increasing trends in the middle and middle-low SDI countries. Although an increasing trend of rate of DALYs in countries with middle and middle-low SDI was observed across all age groups, the trends were not statistically significant at 0.05 in several age groups. Age- and genderspecific trends were more decreasing in countries with low SDI compared with countries with high and high-middle SDI (Table 2).

\section{Discussion}

In this study we showed that the rates of DALY attributed to IV have been consistently decreasing across different social development categories for 1990-2015, except for some age groups. However, the trend of DALYs due to CV has been decreasing in countries with high, high-middle and low social development and increasing in countries with middle and middle-low development (Such as Iraq and Syria). We also showed that the global trends of DALYs rate attributed to IV were more decreasing among women and children, while the global trends of DALYs attributed to $\mathrm{CV}$ were increasing among children.

Although the trend of DALYs attributed to IV has been decreasing, even if the current situation continues, we will have to wait for at least 10 years to reduce the current DALYs down to around $90 \%$ as IRR per year was estimated at 0.989 (95\% CI: 0.988, 0.991). In case of CV, the situation is worsening as estimated IRR per year was at 1.02. It means that DALYs due to this type of violence would increase up to $120 \%$ by the next 10 years. These findings may be interpreted as a failure or insufficiency of the currently implemented global violence preventive programs. ${ }^{3}$ However, this interpretation is from a global point of view, not the individual countries. In other words, the concept of ecological fallacy must be kept in mind in order to interpret these results appropriately. ${ }^{14}$

Our findings show that in most age groups across different social development strata, the burden of interpersonal violence was decreasing more among women. It may be evidence of greater effectiveness of violence preventive programs which have aimed to reduce different types of gender-related violence such as intimate partner violence. ${ }^{15-17}$ The higher level of public demands to reduce gender-related violence may be a probable cause of this finding. ${ }^{18,19}$ A more decreasing trend was observed among children.

According to the study results on the trends of IV, the highest decreasing rates were observed among countries with high and high-middle social development, while this rate was the lowest for countries with low social 
Table 2. Relative Change (Per 10 Years)* of DALYs Rate Attributed to Collective Violence and Legal Intervention, 1990-2015, According to the SDI and Gender

\begin{tabular}{|c|c|c|c|c|c|c|c|}
\hline Age $(y)$ & Gender & L-SDI & LM-SDI & M-SDI & HM-SDI & H-SDI & Global \\
\hline \multirow{2}{*}{$<5$} & M & $-0.70(0.80,0.60)$ & $10.4(10.3,10.5)^{\$}$ & $10.5(10.3,10.6)$ & $-0.51(0.60,0.42)$ & $-0.40(0.60,0.20)$ & $0.29(0.21,0.39)$ \\
\hline & $\mathrm{F}$ & $-0.70(0.80,0.60)$ & $10.4(10.3,10.5)$ & $10.5(10.4,10.7)$ & $-0.50(0.60,0.40)$ & $-0.35(0.60,0.10)$ & $0.30(0.20,0.40)$ \\
\hline \multirow{2}{*}{$5-14$} & M & $-0.60(0.70,0.50)$ & NS & NS & $-0.73(0.89,0.53)$ & NS & NS \\
\hline & $\mathrm{F}$ & $-0.70(0.80,0.60)$ & NS & $0.80(0.60,0.90)$ & $-0.74(0.90,0.50)$ & NS & NS \\
\hline \multirow{2}{*}{$15-19$} & M & $-0.60(0.63,0.58)$ & $0.20(0.10,0.30)$ & $10.4(10.3,10.5)$ & $-0.48(0.59,0.41)$ & $-0.32(0.55,0.25)$ & NS \\
\hline & $\mathrm{F}$ & $-0.58(0.62,0.53)$ & NS & NS & $-0.50(0.70,0.40)$ & $-0.22(0.51,0.10)$ & NS \\
\hline \multirow{2}{*}{$20-24$} & M & $-0.61(0.63,0.59)$ & $0.20(0.10,0.30)$ & $10.2(10.1,10.3)$ & $-0.49(0.58,0.38)$ & $-0.29(0.37,0.19)$ & NS \\
\hline & $\mathrm{F}$ & $-0.55(0.60,0.51)$ & $0.20(0.02,0.40)$ & NS & $-0.40(0.60,0.21)$ & $-0.25(0.51,0.14)$ & NS \\
\hline \multirow{2}{*}{$25-29$} & M & $-0.63(0.65,0.61)$ & $0.16(0.10,0.24)$ & NS & $-0.51(0.62,0.40)$ & $-0.35(0.54,0.16)$ & NS \\
\hline & $\mathrm{F}$ & $-0.48(0.53,0.43)$ & NS & NS & $-0.30(0.40,0.11)$ & NS & NS \\
\hline \multirow{2}{*}{$30-34$} & M & $-0.61(0.63,0.59)$ & $0.10(0.05,0.15)$ & NS & $-0.53(0.57,0.38)$ & $-0.30(0.53,0.10)$ & NS \\
\hline & $\mathrm{F}$ & $-0.45(0.50,0.40)$ & NS & NS & $-0.20(0.39,0.11)$ & NS & NS \\
\hline \multirow{2}{*}{$35-39$} & M & $-0.55(0.58,0.53)$ & $0.10(0.01,0.20)$ & $0.78(0.69,0.91)$ & $-0.52(0.62,0.43)$ & $-0.30(0.54,0.13)$ & NS \\
\hline & $\mathrm{F}$ & $-0.48(0.53,0.43)$ & NS & NS & $-0.28(0.35,0.13)$ & NS & NS \\
\hline \multirow{2}{*}{$40-44$} & M & $-0.45(0.48,0.43)$ & NS & $0.62(0.53,0.73)$ & $-0.40(0.52,0.32)$ & $-0.22(0.43,0.14)$ & NS \\
\hline & $\mathrm{F}$ & $-0.48(0.53,0.43)$ & NS & $0.68(0.54,0.89)$ & $-0.41(0.52,0.20)$ & NS & NS \\
\hline \multirow{2}{*}{$45-49$} & M & $-0.30(0.33,0.27)$ & $0.13(0.01,0.20)$ & $0.62(0.53,0.68)$ & $-0.30(0.40,0.20)$ & NS & NS \\
\hline & $\mathrm{F}$ & $-0.44(0.49,0.40)$ & NS & $0.71(0.41,0.92)$ & $-0.40(0.50,0.20)$ & NS & NS \\
\hline \multirow{2}{*}{$50-69$} & M & $-0.18(0.22,0.15)$ & NS & $0.64(0.44,0.75)$ & $-0.23(0.33,0.12)$ & $-0.25(0.40,0.15)$ & NS \\
\hline & $\mathrm{F}$ & $-0.44(0.50,0.38)$ & $0.20(0.10,0.30)$ & $0.60(0.30,0.80)$ & $-0.29(0.53,0.11)$ & NS & NS \\
\hline \multirow{2}{*}{+70} & M & $-0.27(0.32,0.22)$ & NS & $0.20(0.11,0.40)$ & NS & NS & NS \\
\hline & $\mathrm{F}$ & $-0.55(0.61,0.49)$ & NS & NS & NS & NS & NS \\
\hline
\end{tabular}

M, Male; F, Female; NS, Not significant at 0.05 alpha level; SDI, socio-demographic index; L, low; LM, middle-low; M, middle; MH, middle-high; H, high.

"Percent change per 10 years was reported. In cases of decreasing trends, percent change was reported as a negative number (i.e., -percent change).

$\$$ Bolded fonts depict an increasing trend.

development. There is a crucial point which may be helpful in appropriate interpretation of these results, as quality of available data for countries with lower social development may be questionable. ${ }^{3,5,20,21}$ However, as the prevention and control of IV is a public demand in countries with higher social development, while it may be a neglected issue by population of countries with lower development, violence preventive programs in these counties were superior compared with less developed countries. ${ }^{6,22,23}$ In addition, some forms of violence against women are supported by cultural and religious norms in regions with lower social development or conservative and maledominated settings. ${ }^{24}$ Accordingly, more international support is needed for control and prevention of IV in less developed countries.

Although CV may have been considered as a masculinized issue, according to the study results, children, adolescents and women are highly affected by these types of violence, as the trends of the burden of CV showed the highest increase for children and adolescents. This finding is in line with previous reports, ${ }^{25,26}$ and may be also a result of institutionalized violence in such settings. ${ }^{27}$ In addition, in female population, the trends were increasing across most age groups. Accordingly, there is a need for adopted violence preventive programs focusing on the prevention and control of violence victimization among children, adolescents and women. ${ }^{28}$
This study had an ecological design, and therefore, its results should not be interpreted on the level of individual countries. Violence control and prevention programs hold different ranks among national priorities according to socio-demographic development. It could be considered as a strong confounder and/or interacting factor. To address this issue, stratified trend analyses were done according to socio-demographic development index. Despite this, a residual confounding effect was unavoidable due to the ecological nature of the study. Although the data provided by the GBD project collaboration has some shortages, it may be the best of the available data on the burden of diseases in a global perspective. ${ }^{29}$

In conclusion, global burden of interpersonal violence has been more decreasing among women and children. By the next 10 years, the global burden of CV and legal interventions would increase up to $120 \%$, if the current situation continues. Children, adolescents and women are highly affected by CV in countries with middle-low and middle social development.

\section{Authors' Contribution}

HMV designed the study. Data collection and data analysis were performed by HMV; AS collaborated in data analysis. HMV wrote the first draft of the manuscript. AS and HMV revised the manuscript.

\section{Conflict of Interest Disclosures}

None. 


\section{Ethical Statement}

This study was a secondary data analysis and no ethical issue was applicable.

\section{Supplementary Materials}

Data are available in Supplementary file 1.

\section{Acknowledgments}

We would like to thank the GBD Project team.

\section{References}

1. Haagsma JA, Graetz N, Bolliger I, Naghavi M, Higashi $H$, Mullany EC, et al. The global burden of injury: incidence, mortality, disability-adjusted life years and time trends from the Global Burden of Disease study 2013. Inj Prev. 2016;22(1):318. doi: 10.1136/injuryprev-2015-041616.

2. Lopez AD, Mathers CD. Measuring the global burden of disease and epidemiological transitions: 2002-2030. Ann Trop Med Parasitol. 2006;100(5-6):481-99. doi: 10.1179/136485906X97417

3. Mikton CR, Butchart A, Dahlberg LL, Krug EG. Global status report on violence prevention 2014. Am J Prev Med. 2016;50(5):652-9. doi: 10.1016/j.amepre.2015.10.007.

4. Modi MN, Palmer S, Armstrong A. The role of Violence Against Women Act in addressing intimate partner violence: A public health issue. J Womens Health (Larchmt). 2014;23(3):253-9. doi: 10.1089/jwh.2013.4387.

5. Palermo T, Bleck J, Peterman A. Tip of the iceberg: reporting and gender-based violence in developing countries. Am J Epidemiol. 2014;179(5):602-12. doi: 10.1093/aje/kwt295.

6. Sumner SA, Mercy JA, Dahlberg LL, Hillis SD, Klevens J, Houry D. Violence in the United States: status, challenges, and opportunities. JAMA. 2015;314(5):478-88. doi: 10.1001/ jama.2015.8371.

7. Hillis S, Mercy J, Amobi A, Kress H. Global prevalence of past-year violence against children: a systematic review and minimum estimates. Pediatrics. 2016;137(3):e20154079. doi: 10.1542/peds.2015-4079.

8. Green LW, Kreuter MW. Health Program Planning: An Educational and Ecological Approach. 4th ed. New York: McGraw-Hill; 2005.

9. Rocha E. The global burden of disease: An information resource for policy-making and evaluation of health interventions. Rev Port Cardiol. 2017;36(4):283-285. doi: 10.1016/j. repc.2017.02.007.

10. Flaxman A. Global Burden of Disease: Determining Priorities on a Global Scale. 2017 AAAS Annual Meeting (February 1620, 2017). Available from: https://aaas.confex.com/aaas/2017/ webprogram/meeting2017-02-17.html.

11. Global Burden of Disease (GBD). Institute for Health Metrics and Evaluation; 2017. Available from: http://www.healthdata. org/gbd.

12. Definition and typology of violence. World Health Organization; 2018. Available from: http://www.who.int/ violenceprevention/approach/definition/en/.

13. World Health Organization. Violence and Injury Prevention: Collective violence. WHO; 2017. Available from: http://www. who.int/violence_injury_prevention/violence/collective/en/.

14. Freedman DA. Ecological inference and the ecological fallacy. In: Smelser NJ, Baltes PB, eds. International Encyclopedia of the social \& Behavioral sciences. Vol 6. New York: Elsevier; 2001:4027-30.

15. Patrick JM, Ugwu AN. Culture and gender-related violence against women in Ogoni ethnic nationality in Nigeria: implications for adult education. Gender and Behaviour. 2013;11(2):5804-11.

16. Alldred P, Biglia B. Gender-Related Violence and Young People: An Overview of Italian, Irish, Spanish, UK and EU Legislation. Child Soc. 2015;29(6):662-75.

17. Langhinrichsen-Rohling J. Controversies involving gender and intimate partner violence in the United States. Sex Roles. 2010;62(3-4):179-93.

18. Bott S, Morrison A, Ellsberg M. Preventing and responding to gender-based violence in middle and low-income countries: a global review and analysis; 2005. Policy, research working paper; no. WPS 3618. Washington, DC: World Bank. Available from: http://documents.worldbank.org/curated/ en/852691468140377416/Preventing-and-responding-togender-based-violence-in-middle-and-low-income-countriesa-global-review-and-analysis.

19. Ameh N, Kene T, Onuh S, Okohue J, Umeora O, Anozie O. Burden of domestic violence amongst infertile women attending infertility clinics in Nigeria. Niger J Med. 2007;16(4):375-7. doi: 10.4314/njm.v16i4.37342

20. Macdonald G. Violence and health: the ultimate public health challenge. Health Promot Int. 2002;17(4):293-5. doi: 10.1093/heapro/17.4.293

21. Matzopoulos R, Bowman B, Butchart A, Mercy JA. The impact of violence on health in low-to middle-income countries. Int J Inj Contr Saf Promot. 2008;15(4):177-87. doi: 10.1080/17457300802396487.

22. Krug EG, Mercy JA, Dahlberg LL, Zwi AB. The world report on violence and health. Lancet. 2002;360(9339):1083-8. doi: 10.1016/S0140-6736(02)11133-0

23. World Health Organization. Violence prevention: the evidence. Geneva: WHO; 2010.

24. Street AE, Gradus JL, Stafford J, Kelly K. Gender differences in experiences of sexual harassment: data from a male-dominated environment. J Consult Clin Psychol. 2007;75(3):464-74. doi: 10.1037/0022-006X.75.3.464

25. Askin KD. Prosecuting wartime rape and other gender-related crimes under international law: extraordinary advances, enduring obstacles. Berkeley J Int'I L. 2003;21:288.

26. Olema DK, Catani C, Ertl V, Saile R, Neuner F. The hidden effects of child maltreatment in a war region: correlates of psychopathology in two generations living in northern Uganda. J Trauma Stress. 2014;27(1):35-41. doi: 10.1002/ jts. 21892 .

27. Kaldor M. New and Old Wars: Organised Violence in a Global Era. London: John Wiley \& Sons; 2013.

28. Ventevogel P, Jordans MJ, Eggerman M, van Mierlo B, PanterBrick C. Child mental health, psychosocial well-being and resilience in Afghanistan: a review and future directions. In: Fernando C, Ferrari M, eds. Handbook of Resilience in Children of War. New York, NY: Springer; 2013:51-79.

29. Molavi Vardanjani H, Heidari M, Hadipour M. Can We Rely on GLOBOCAN and GBD Cancer Estimates? Case Study of Lung Cancer Incidence and Mortality Rates and Trends in Iran. Asian Pac J Cancer Prev. 2016;17(7):3265-9. 